\title{
Multimídia na alfabetização digital com fluência para a autoria
}

Liane Tarouco, CINTED/UFRGS, liane3@ penta.ufrgs.br

Barbara Ávila, Instituto de Matemática / UFRGS, Barbara@ cinted.ufrgs.br

\section{Resumo}

Este artigo descreve os princípios norteadores de uma estratégia de capacitação de docentes em serviço e estudantes de cursos de licenciatura em programas e cursos envolvendo alfabetização digital voltados à aquisição de fluência em tecnologia de informação e comunicação ou seja, visando a capacitação para a autoria. São apresentadas e exemplificadas as estratégias utilizadas, baseadas em multimídia, e a avaliação das mesmas por um grupo de estudantes.

Palavras-chave: Alfabetização digital, fluência em TIC, multimídia

\begin{abstract}
This article describes the principles guiding a strategy for qualification of students and teachers in service in capacity programs aiming digital literacy directed to acquisition of fluency in information technology aiming at the qualification toward the authorship. Used strategies (based in multimedia) and examples of produced materials are presented as well as an evaluation of the resources and strategies by a group of students.
\end{abstract}

Keywords: digital literacy, fluency in information technology, multimídia

\section{Alfabetização digital}

Alfabetização digital é hoje, no contexto das chamadas Sociedades da Informação, um dos pontos mais críticos no processo de inclusão digital. Alfabetização digital está relacionada à aquisição de habilidades básicas para o uso de computadores e da Internet.

Pesquisas e estudos realizados têm demonstrado uma significativa melhoria na qualidade dos processos de ensino e aprendizagem nas escolas públicas do país a partir da implementação de programas voltados à difusão do uso de Tecnologias de Informação e Comunicação (TICs) no ensino público. Felitti (2007) relata resultados derivados de estudo publicado pelo INEP e que revela que os alunos de escolas que têm laboratórios de informática tiraram notas mais baixas em matemática no SAEB (o exame nacional de avaliação do ensino básico). Mas nas escolas que usam os computadores para acessar a Internet e ensinar as disciplinas, as notas dos alunos foram mais altas que a média. $\mathrm{O}$ estudo usou dados coletados pelo Sistema de Avaliação da Educação Básica (SAEB) nos anos de 1999, 2001 e 2003 entre amostras de alunos de matemática da $4^{\mathrm{a}}$ série do ensino fundamental em colégios públicos brasileiros.

$\mathrm{Na}$ métrica desenvolvida pelo INEP para avaliar o impacto que os diversos fatores considerados têm no desenvolvimento pedagógico dos alunos, a presença de computadores no colégio levou a uma queda de 5,95 pontos no número constante definido para as escolas. O uso de internet, pelo lado contrário, elevou o número em 5,63 pontos, fazendo com que escolas apresentassem "maior eficiência que se reflete sobre o desempenho", o que fez com que o INEP classificasse o coeficiente como de grande impacto no resultado final do 
estudo. Este e outros estudos apontam que não basta tornar um tipo de tecnologia disponível na escola para que os almejados efeitos positivos na aprendizagem ocorram.

Governos federal, estaduais e municipais tem investido considerável quantidade de recursos para promover a universalização do acesso às tecnologias da informação e comunicação (TIC) e na preparação dos indivíduos para fazerem uso delas. Em consequiência percebese uma demanda crescente de estratégias eficazes para promover a chamada alfabetização digital dos professores para que se tornem capacitados a utilizar, de forma eficaz, os recursos que passam a ser disponibilizados nas escolas.

Importante destacar que tanto os alunos quanto os professores, embora "alfabetizadas" no mundo digital, necessitam de "algo mais para efetivamente funcionar na sociedade da informação". Isto implica na noção de fluência referida no livro verde da Sociedade da Informação como sendo a "capacidade de reformular conhecimentos, expressar-se criativa e apropriadamente, bem como produzir e gerar informação". Esta definição citada no livro verde da Sociedade da Informação, deriva de um estudo do Comitê de Alfabetização em Tecnologias de Informatização (Committee of Information Technology Literacy), instituído pelo Conselho Nacional de Pesquisas dos EUA, o qual divulgou em 1999 um relatório de trabalho em que foi proposta a noção de fluência (em Tecnologias de Informação) em contraposição à alfabetização, para denotar a "capacidade de reformular conhecimentos, expressar-se criativa e apropriadamente, bem como produzir e gerar informação (em vez de meramente compreendê-la)". O objetivo dessa revisão conceitual era endereçar o problema de pessoas que, embora "alfabetizadas" no mundo digital, necessitavam de algo mais para efetivamente participar de forma ativa na sociedade da informação.

Isto é especialmente mais relevante no momento atual onde de usuários passivos/leitores das informações que fluem pela Internet, os usuários passam a ter a possibilidade de assumir o papel de criadores de informação seguindo a tendência da segunda geração da World Wide Web (Web 2.0), que enfatiza o conceito de troca de informações e colaboração dos internautas com sites e serviços virtuais nos quais participam não apenas como leitores mas também como autores e organizadores de conteúdo.

Percebendo a necessidade de promover a capacitação de educadores para o uso pedagógico das mídias integrado à proposta pedagógica o Ministério de Educação, através da Secretaria de Educação à Distância, iniciou em 2005 o Programa de Formação Continuada em Mídias na Educação. O programa tem como uma de suas principais características a integração das diferentes mídias ao processo de ensino e de aprendizagem, promovendo a diversificação de linguagens e o estímulo à autoria em diferentes mídias.

Tendo participado do projeto e desenvolvimento de módulos voltados à capacitação dos docentes no uso da mídia Informática, foi desenvolvido um estudo que subsidiasse o processo de delinear uma estratégia capaz de superar as dificuldades usualmente enfrentadas pelos docentes na trajetória em direção fluência em tecnologia da Informação especialmente tendo em vista a necessidade de capacitar para a produção de conteúdo, utilizando diferentes ferramentas de autoria. Os resultados derivaram uma série de estratégias a serem utilizadas em material educacional digital voltado para a capacitação de docentes e de estudantes de licenciatura e foram testadas em cursos de capacitação de professores da rede pública estadual e municipal (formação em serviço) promovidos e apoiados pelo MEC/SEED e também com estudantes de cursos de licenciatura em 
Pedagogia, Matemática, Geografia e outros na UFRGS. Tal capacitação buscou ensejar o desenvolvimento de habilidades para utilizar ferramentas de autoria voltadas à produção de material textual e multimídia. Diversas experiências mostraram que atualmente, a maioria dos docentes e estudantes de licenciaturas tem conhecimentos e habilidades básicas relativas ao uso do computador e da Internet, sendo capazes de produzir textos simples, usando um editor de texto, acessar o serviço WWW e utilizar serviço de correio eletrônico. Todavia, quando se trata de compor ou editar imagens, utilizando um editor gráfico, compor e produzir material educacional digital que contenha multimídia (apresentações, páginas para o WWW) o nível de desconhecimento é o que se verifica na maioria dos docentes.

Buscando uma estratégia que pudesse ser também utilizada em curso desenvolvidos utilizando educação à distância foi delineada uma abordagem, utilizando multimídia a qual será resumida a seguir.

\section{Usando a multimídia}

O desenvolvimento de material educacional digital de qualidade não prescinde o uso de multimídia pois sua utilização tem sido amplamente reconhecido pelo potencial aprimoramento na forma como as pessoas aprendem (Mayer 2002). Todavia, conforme destacado também por Mayer em outro trabalho (2001) o uso de mais de uma mídia concorre pela atenção do estudante e seu uso indiscriminado e de forma não apropriada pode afetar negativamente o processo de reflexão, ou como ele denomina, "o fazer sentido" por inúmeras razões.

Numa sociedade com as possibilidades tecnlógicas da atual, a mediação textual da aprendizagem e da construção do conhecimento não pode limitar-se apenas ao texto como livro já que a tecnologia evoluiu e permite maior variedade de possibilidades. O projeto deste tipo de material deve levar em conta tanto considerações derivadas de teorias de aprendizagem como combinar o conhecimento de outras áreas como ergonomia, engenharia de sistemas e levar ainda em conta as potencialidades e limitações da tecnologia envolvida e isto significa atualmente utilizar a multimídia como recurso de apoio no processo de ensino-aprendizagem. Portanto, no delineamento da estratégia para capacitar os docentes e alunos de cursos de licenciatura para o uso da tecnologia da informação e comunicação, considerou-se que era essencial utilizar recursos de multimídia para apoiar e motivar o aluno com vistas a suprir ao menos parcialmente a ausência de interação/atenção presencial. A multimídia foi usada para proporcionar autonomia ao aluno na manipulação das ferramentas de autoria e estratégia pedagógica utilizada envolveu:

a. Materiais contextualizando e justificando

b. Tutoriais passo a passo

c. Projetos de pequeno escopo

d. Interação

\subsection{Materiais contextualizando e justificando}

Estes tipo de suporte tinha como objetivo ressaltar a importância no uso de cada uma das ferramentas de autoria . Estes materiais apresentavam e discutiam aportes teóricos inerentes 
ao uso do recurso em estudo. Por exemplo, antecedendo o processo de capacitação para o uso de ferramentas de edição gráfica, eram apresentados vídeos (produzidos pela TV Escola) e materiais multimídia além de outros puramente textuais, que destacavam a importância da imagem na educação. Um exemplo de resultado pode ser encontrado no material desenvolvido para o curso de Licenciatura em Pedagogia à distância (Tarouco 2006b), figura 1 .

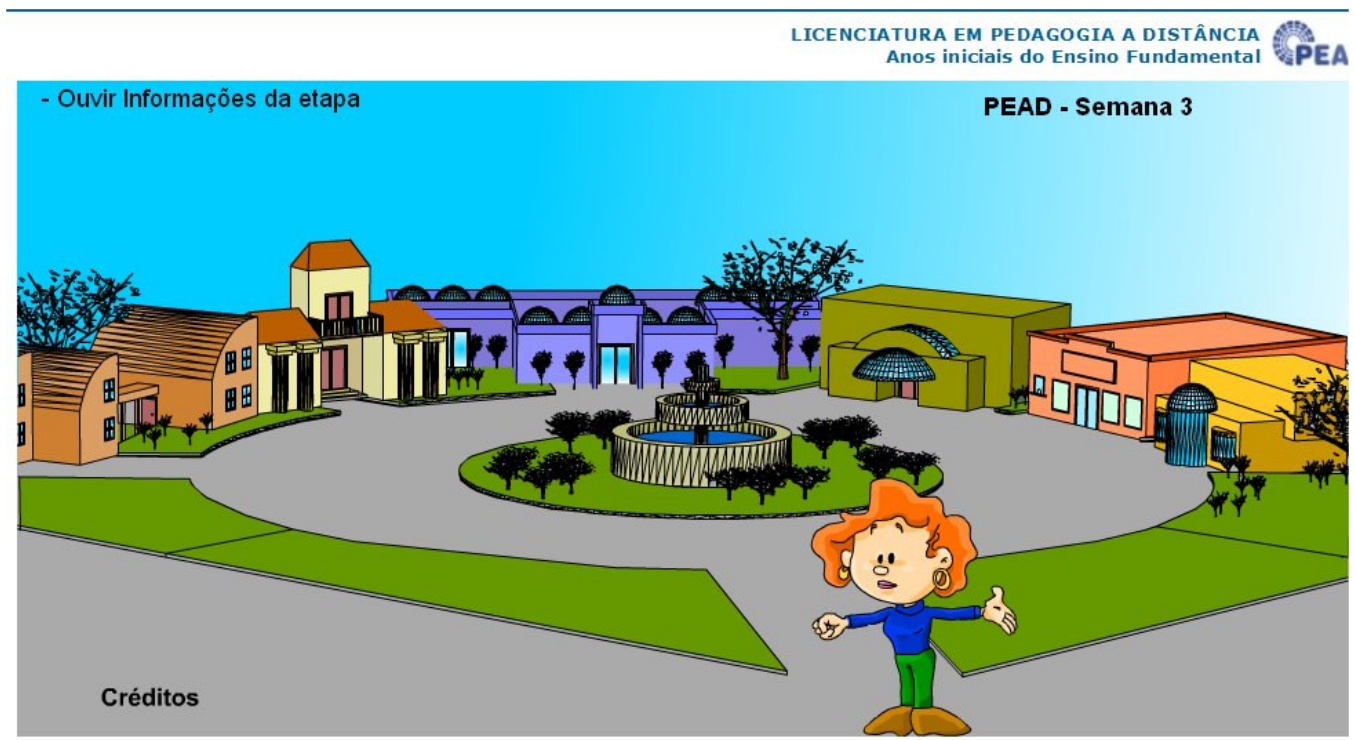

Figura 1: A Cidade virtual PEAD

Neste exemplo não foi utilizado áudio nos tutoriais em função da constatação de que a maioria dos estudantes disporem de acesso Internet estabelecido mediante rede telefônica discada, com velocidade igual ou inferior a $56 \mathrm{Kbps}$ o que tornaria muito lento o processo de acessar tutoriais que utilizassem trilha de áudio.

No acesso inicial ao material foi utilizada a metáfora de uma cidade onde o estudante encontraria a escola (com explicações, tutoriais, materiais de apoio), uma biblioteca (com o conjunto de todos os tutoriais do curso organizados), um cinema (onde seria encontrados links para os vídeos indicados em cada etapa), um salão de jogos (onde seriam encontrados alguns jogos educativos para que o estudante pudesse, de forma lúdica, realizar uma autoavaliação) e um café (onde encontraria a orientação e incentivo para a participação das discussões em grupo). Neste cenário, aparece uma personagem que realiza a fala de apresentação do escopo da unidade a ser trabalhada. Este é um momento em que foi utilizado áudio com o intuito de que esta locução, juntamente com o avatar, a personagem que apresenta o material e que tinha um pequeno nível de animação simulando o gestual de quem fala, se conseguisse motivar o estudante para o trabalho sendo iniciado. Este avatar foi desenvolvido a partir de um trabalho interdisciplinar mediante colaboração com Biazuz (2004).

\subsection{Tutoriais passo-a-passo}

O tipo de tutorial desenvolvido para apoiar esta estratégia tem demonstrações dinamicamente ilustradas (animações) com sequiências de passos simulando o uso dos mecanismos disponíveis na ferramenta de autoria. Estes tutorais são construídos utilizando 
ferramentas que permitem capturar cada etapa do processo de utilização de uma ferramenta de autoria e posteriormente o material capturado é comentado e pode receber narrativas em áudio explicando cada um dos passos. Um exemplo de tutorial é apresentado na figura 2 e o acesso ao mesmo pode ser feito através da biblioteca na cidade virtual (Tarouco 2006).

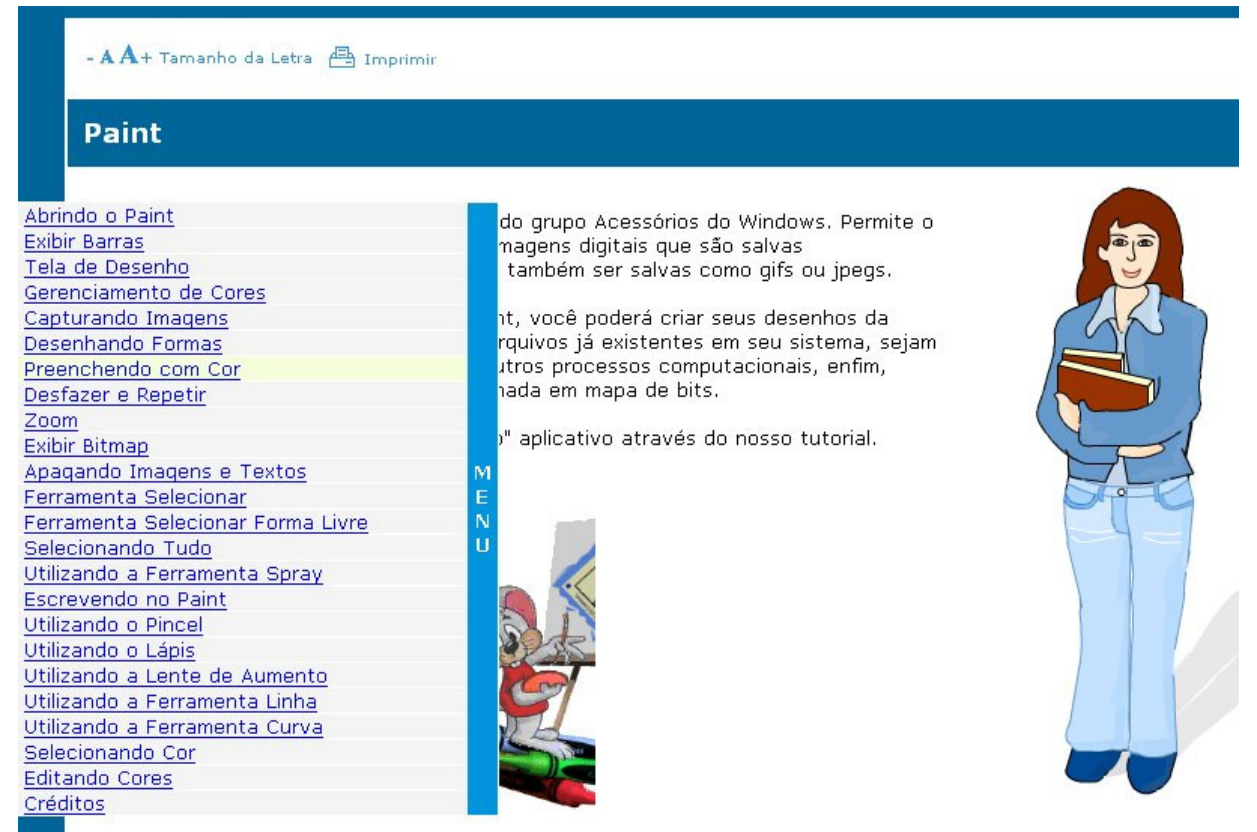

Figura 2: Tutorial

Neste tutorial o avatar animado com trilha de áudio presente na entrada do material, foi substituído por uma figura que criasse uma empatia com a estudante. A trilha de áudio e a animação não foram extensivamente utilizadas ao longo de todo o tutorial pelos motivos anteriormente explicados, ou seja, baixa velocidade no acesso à Internet.

Também foi utilizado um menu retrátil que permitisse ampliar a área disponível para uso pelo tutorial em si sem eliminar a possibilidade de, a qualquer momento, ser acessado o menu que permitiria a navegação "por demanda" isto é, segundo o caminho que melhor atendesse à necessidade e/ou curiosidade da estudante. Assim o tutorial tanto poderia ser trilhado na forma seqüencialmente sugerida no material como na modalidade por demanda.

O texto foi construído buscando utilizar uma linguagem coloquial para ensejar/estimular um processo dialógico. Os desafios da concepção de cursos a distância e seus materiais didáticos são complexos e não podem ser minimizados. Os meios são agentes ativos dos processos de construção e de representação da realidade. Assim para cativar e manter interessado o estudante do tutorial são utilizadas estratégias tais como dialogismo e simplificação. O professor autor do material "fala" com o estudante através do texto e em lugar de utilizar uma linguagem mais neutra, tal como recomendado para publicações científicas, nos tutoriais voltados para o auto-estudo, podem e devem utilizar um estilo de comunicação mais pessoal, com pronomes e verbos na primeira e segunda pessoa sendo usados nas orientações. Adicionalmente é recomendável utilizar moderada intensidade de informação em cada passo. Ressalte-se que isto não significa que o processo de aprendizagem como um todo deva ser pautado por estas orientações mas elas se aplicam 


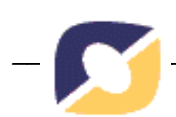

aos tutoriais. O tutorial deve aconselhar e orientar o estudante sobre o que tem que fazer, o que evitar (dicas) o que é mais importante, o que é acessório etc... Outros textos de referência, mais complexos e aprofundados, também devem constar no material de apoio que vai ser oferecido ao estudante para subsidiar seu processo de aprendizagem. Além disso o estudante é orientado a pesquisar na Internet fontes alternativas de informação e suporte procurando informações mais aprofundadas.

Em cada página no tutorial uma demonstração animada mostra, passo-a-passo os procedimentos necessários para usar aquela ferramenta. Os estudantes manifestam aprovação pela estratégia externando sua aceitação deste tipo de tutoriais através de expressões tais como: "dêem-me um tutorial passo-a-passo e eu faço qualquer coisa". Percebe-se que os tutoriais contribuem para reduzir o temor pelo fracasso que freqüentemente leva à evasão alunos de EAD.

\subsection{Projetos de pequeno escopo}

Projetos de pequeno escopo desenvolvidos pelos alunos, que demandavam o uso das características da ferramenta que era objeto de ensino-aprendizagem, tal como apresentadas nos tutoriais mas que davam abertura para que o tema, grau de abrangência ou profundidade do resultado pudesse ser definido pelo próprios estudantes.

Esta estratégia permite orientar o processo de ensino-aprendizagem segundo um paradigma de construção de conhecimento direcionado pelo aluno em função do que deseja conhecer e o que já sabe e principalmente voltado a ensaiar a futura atividade de preparar material de apoio e subsídio para sua própria atividade docente.

\subsection{Interação com, tutores e demais colegas}

A interação com professor, tutores e demais colegas para dirimir dúvidas visa o estabelecimento de comunidades virtuais de aprendizagem pois, conforme defendido em (Tarouco 2006b), desta forma cria-se oportunidade para o trabalho em rede e o desenvolvimento da capacidade de cooperar, aprender, acessar e produzir informação, que será uma habilidade exercida não apenas na fase formal do processo educacional, mas principalmente no decorrer da carreira de cada um, pois a educação continuada constitui uma demanda imperiosa do mercado de trabalho, em constante transformação.

É importante construir o hábito da aprendizagem colaborativa. O estudante deve ser incentivado a participar de fórum, bate-papo ou outra forma de interação mediada por computador . O próprio tutorial deve promover a interação e o diálogo através de perguntas não respondidas que demandam o debate, a reflexão colaborativa e argumentos que fomentam e ampliam a compreensão.

Ressalte-se que nas situações onde o tipo de conexão com a Internet dos estudantes permite o uso de uma comunicação mais rica, envolvendo áudio e vídeo, em forma interativa tal como na videoconferência, percebe-se nitidamente um entusiasmo e uma participação mais ativa dos estudantes. Aulas mediadas por videoconferência foram disponibilizadas em alguns cursos de capacitação e a ferramenta utilizada para estas aulas foi o Macromedia Breeze disponível na UFRGS que permitia, além de janelas com vídeo e áudio do professor 
também a participação dos estudantes que tivessem webcam e microfone, tal como ilustrado na figura 3. Adicionalmente esta ferramenta permite apresentar simultaneamente uma janela com quadro branco ou uma apresentação de slides ou realizar uma demonstração de algum aplicativo sendo executado no computador do professor e podendo ser acompanhado pelos estudantes em tempo real. Isto permite realizar demonstrações sob demanda, isto é, para responder a consultas ou elucidar dúvidas dos estudantes.

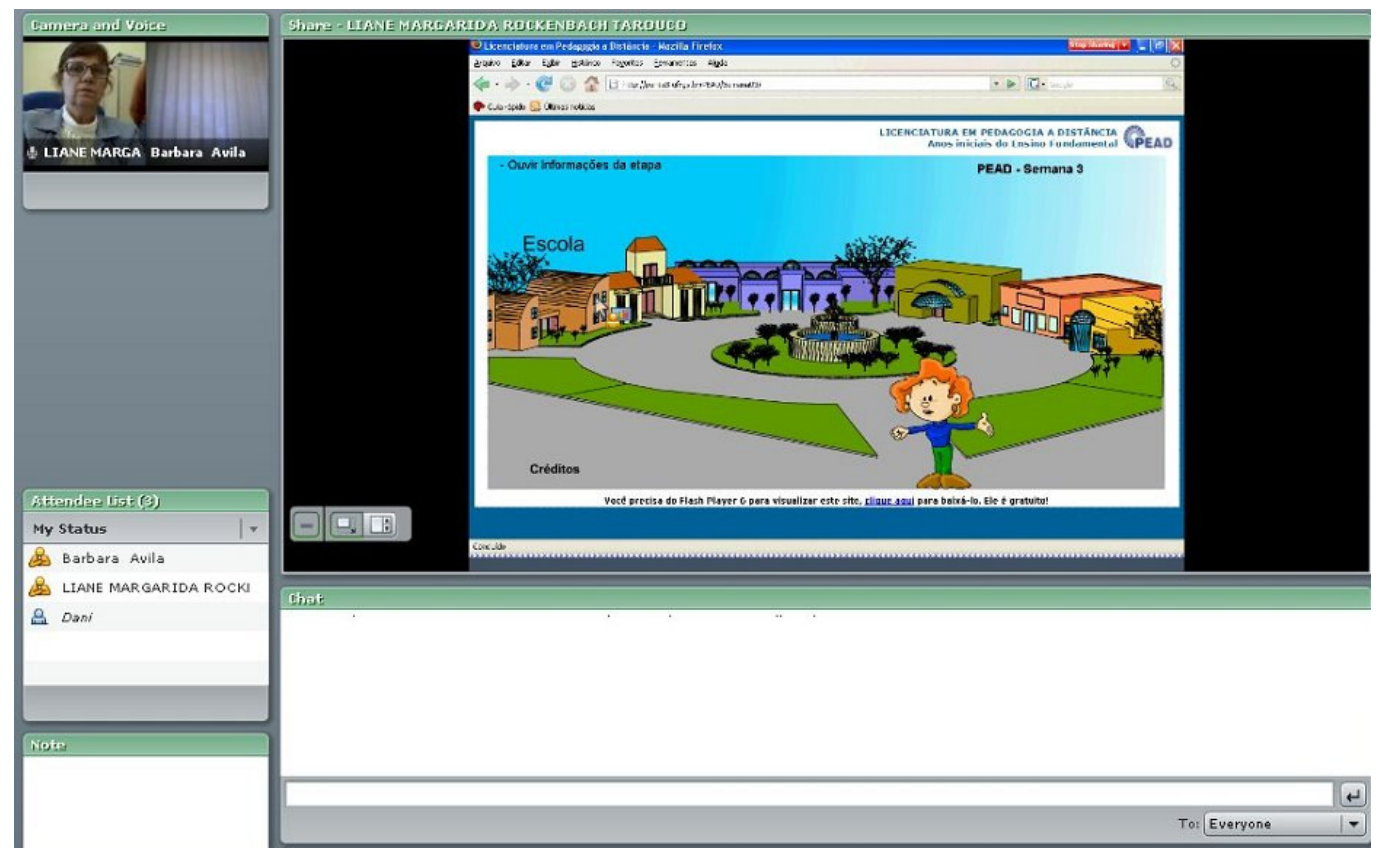

Figura 3: Interação por videoconferência

A oportunidade de manifestação por áudio e vídeo dos estudantes funciona como elemento importante na motivação dos demais, mesmo para aqueles que não dispõem de webcam e recurso de áudio e cuja interação é realizada através da ferramenta de chat também disponível neste ambiente.

\section{Relato de experiências}

Uma investigação foi realizada para obter uma avaliação desta estratégia. Neste sentido, uma atividade de análise sobre os recursos de aprendizagem utilizados durante o curso foi proposta aos estudantes e buscou identificar indícios que permitissem avaliar a efetividade das estratégias adotadas.

Nos textos postados pelos estudantes constatou-se uma valorização do papel dos tutoriais passo a passo utilizados durante o processo de ensino-aprendizagem. Alguns exemplos de depoimentos demonstram a receptividade da estratégia:

- "Os tutoriais juntamente com a possibilidade de ver as produções dos colegas e de ter acesso às suas opiniões foram de grande valia para a execução dos trabalhos e principalmente a construção de novos conhecimentos para uso extra curricular, ampliando os horizontes para a análise crítica, ganhando de bandeja a visão dos 
colegas, para a partir delas, desenvolver novos raciocínios e fazer novas colaborações." (G. S. B. - graduação)

- "Os tutoriais foram um elo entre os alunos e os docentes." (C.C., graduação). Os tutoriais, muitas vezes, representam um elo entre os grupos docente e discente, mimetizando a figura do professor, com suas demonstrações passo a passo, conforme já fora mencionado anteriormente

- "Na parte ilustrativa, os tutoriais são bem elaborados. Alguns alcançam verdadeiramente o objetivo de nortear o aprendiz, visto que estão construídos passo à passo. E para que é principiante nas tecnologias , ensina de forma eficaz." (A. A. pós-graduação)

- "O uso de vídeo-conferências através do breeze foi excelente. A associação de voz e imagem trouxe uma riqueza de recursos para nossas aulas. Estávamos tendo aula expositiva e síncrona em EAD! O vídeo deu a sensação de proximidade, minimizou uma sensação comum na EAD: sentir-se só!" (A. N. - pós-graduação)

- Os tutoriais são uma das formas de comunicação entre alunos e direção da disciplina, ajudaram, no meu processo de ensino-aprendizagem, a instigar dúvidas e a buscar respostas sobre os assuntos tratados. O bate papo foi pra mim um auxiliador nos processos práticos dos mecanismos dos programas utilizados, um auxílio às dúvidas mais básicas, e os fóruns, foram muito importantes para debate entre os colegas sobre suas opiniões

\section{Conclusões}

Conforme defendido por Astleitner e Wiesner (2004) a motivação influencia a aprendizagem e em especial a atenção que constitui um fator relevante. Isto é importante, uma vez que o processo de aprendizagem humana é apoiado pelo uso de recursos limitados (capacidade da memória visual e auditiva que atuam como memória de trabalho e constituem gargalos no processo de aquisição de informação). Assim o processo de aprendizagem pode ser considerado como um processo de gerenciamento de recursos escassos (atenção) controlado por parâmetros motivacionais. A seletividade intencional na atenção facilita o processamento da informação relativo à intenção atual e inibe o processamento de informação em direções divergentes (distrações).

A investigação desenvolvida comprovou que tutoriais passo a passo com multimídia cativam a atenção do estudante ensejando uma aprendizagem melhor orientada e apoiada e proporcionando a aquisição de maior independência na capacitação para o uso das ferramentas de autoria trabalhadas, dirimindo o temor pelo fracasso o que constitui elemento de redução de motivação sendo também responsável por uma maior taxa de abandono em cursos que utilizam educação a distância. $O$ uso de avatares e texto construído com preocupações dialógicas contribui para reduzir a sensação de distância entre o estudante de EAD e os professores, tutores e colegas.

Mediação por chat e videoconferência ensejam reflexão coletiva e troca de experiências que também contribuem para aumentar motivação.

\section{Referências}


ASTLEITNER, H, WIESNER. C, Na Integrated Modelo f Multimedia Learning and Motivation. Journal og Educational Multimedia and Hypermedia (2004) 13 (1), 3-21

Biazuz. Maria C. AprenDI - Aprendizagem Dinamizada por Objetos. UFRGS. 2004. Projeto acessível em: http://www6.ufrgs.br/aprendi/. Acesso em outubro/2007

Felitti. Guilherme. Brasil: Internet compensa impacto negativo de PCs em escolas, afirma estudo do MEC. RITLA - Rede de Informação Tecnológica Latino Americana. Agosto/2007. Acessada em outubro/2007 em http://www.ritla.net/index.php?option=com_content\&task=view\&id=1021\&Itemid=215

GRANDO, Anita Raquel Cestari da Silva. Tarouco, Liane Margarida Rockenbach. Alfabetização visual para a produção de objetos educacionais. Revista Novas Tecnologias na Educação, Porto Alegre - RS, v. 1, n. 2, 2003.

GRANDO, Anita Raquel Cestari da Silva. Tarouco, Liane Margarida Rockenbach. Animações multimídia para apoiar o processo de construção do conhecimento : In: Salão de Iniciação Cientfica (14. : 2002 : Porto Alegre) Livro de resumos. Porto Alegre : UFRGS/PROPESQ, 2002. p. 841

MAYER, R., MORENO, R. Animation as na Aid to Multimedia Learning. Educational Psychology Review, Vol 14, No 1, March 2002

MAYER, R. E. ; HEISER, J. ; LONN, S. ; Cognitive constraints and multimedia learning: when presenting more material results in less understanding ; Journal of education psychology 2001, vol. 93, n. 1, 187-198.

MEC/SEED. Programa de Formação Continuada em Mídias na Educação • Brasília 2005.

PALLOFF, Rena M. O aluno virtual : um guia para trabalhar com estudantes on-line. Porto Alegre: ArtMed, 2004. 261 p.

Takahashi, T. Sociedade da Informação no Brasil, MCT. Brasília Setembro/2000.

TAROUCO, Liane. Comunidade de Aprendizagem em Rede. In Integração das Tecnologias na Educação. MEC TV. Escola. 2006. Acessados em Outubro/2007. Disponível em: http://portal.mec.gov.br/seed/arquivos/doc/sf_integra\%C3\%A7\%C3\%A3o_tecnologias.doc

TAROUCO, Liane. Trabalhando com imagens. In.: Licenciatura em Pedagogia a distância. FACED. 2006. Acessível em http://penta3.ufrgs.br/PEAD/Semana03/semana3ImagensMaterialApoio.html. Acessado em Outubro/2007. 